\title{
In Vitro Degradation Behaviors of Manganese-Calcium Phosphate Coatings on an Mg-Ca-Zn Alloy
}

\author{
Yichang Su, ${ }^{1}$ Yingchao Su, ${ }^{1}$ Wei Zai, ${ }^{1}$ Guangyu Li $\left(\mathbb{D},{ }^{1}\right.$ and Cuie Wen ${ }^{2}{ }^{2}$ \\ ${ }^{1}$ Key Laboratory of Automobile Materials, Ministry of Education, College of Materials Science and Engineering, \\ Jilin University, Changchun 130025, China \\ ${ }^{2}$ School of Engineering, RMIT University, Melbourne, VIC 3001, Australia
}

Correspondence should be addressed to Guangyu Li; guangyu@jlu.edu.cn and Cuie Wen; cuie.wen@rmit.edu.au

Received 9 June 2017; Revised 8 October 2017; Accepted 31 October 2017; Published 13 February 2018

Academic Editor: Daniele Passeri

Copyright (C) 2018 Yichang Su et al. This is an open access article distributed under the Creative Commons Attribution License, which permits unrestricted use, distribution, and reproduction in any medium, provided the original work is properly cited.

\begin{abstract}
In order to decrease the degradation rate of magnesium $(\mathrm{Mg})$ alloys for the potential orthopedic applications, manganese-calcium phosphate coatings were prepared on an $\mathrm{Mg}-\mathrm{Ca}-\mathrm{Zn}$ alloy in calcium phosphating solutions with different addition of $\mathrm{Mn}^{2+}$. Influence of Mn content on degradation behaviors of phosphate coatings in the simulated body fluid was investigated to obtain the optimum coating. With the increasing Mn addition, the corrosion resistance of the manganese-calcium phosphate coatings was gradually improved. The optimum coating prepared in solution containing $0.05 \mathrm{~mol} / \mathrm{L} \mathrm{Mn}^{2+}$ had a uniform and compact microstructure and was composed of $\mathrm{MnHPO}_{4} \cdot 3 \mathrm{H}_{2} \mathrm{O}, \mathrm{CaHPO}_{4} \cdot 2 \mathrm{H}_{2} \mathrm{O}$, and $\mathrm{Ca}_{3}\left(\mathrm{PO}_{4}\right)_{2}$. The electrochemical corrosion test in simulated body fluid revealed that polarization resistance of the optimum coating is $36273 \Omega \mathrm{cm}^{2}$, which is about 11 times higher than that of phosphate coating without $\mathrm{Mn}$ addition. The optimum coating also showed the most stable surface structure and lowest hydrogen release in the immersion test in simulated body fluid.
\end{abstract}

\section{Introduction}

Orthopedic surgery in recent times depends profoundly on the development of biomaterials used for fixation of fractures and joint replacement [1]. Among the three main kinds of biological implant materials, metallic materials, ceramic materials, and polymeric materials, biodegradable metals and polymers have gained interest for their advantages of being gradually dissolved, absorbed, consumed, or excreted in the human body, so there is no need for the secondary surgery to remove implants after the surgery regions have healed [2]. Current biodegradable implants made of polymers have an unsatisfactory mechanical strength [3] and therefore limited applications. Thus, magnesium $(\mathrm{Mg})$ and its alloys have been attracting growing attention as next-generation medical material suitable for biodegradable bone implant and stent due to their well physical and mechanical properties, such as excellent biocompatibility, high strength, and similar elastic modulus to human bone [4-7]. However, the rapid decomposition speed of $\mathrm{Mg}$ alloys hinders the implants to fulfill their surgical function before being discharged, the inhomogeneous local corrosion starting from the surface of $\mathrm{Mg}$ alloys makes the corrosion behavior uncontrollable, and too much hydrogen evolved can be accumulated in gas pockets next to the corroding $\mathrm{Mg}$ implant, which will delay healing of the surgery region and lead to inflammatory reaction.

Attempts to improve the corrosion resistance performance have been made on various $\mathrm{Mg}$ alloys, such as on AZ91 [8, 9], AZ31 [10, 11], AM60 [12], ZM21 [13], Mg-Ca [14], Mg$\mathrm{Zn}$ and Mg-Mn [15], Mg-Zr-Sr [16], and Mg-Zn-Ca. Among these $\mathrm{Mg}$ based alloys, AZ91 and AM60 contain Al which is indicated in several pathological conditions in the human, the most commonly associated ones include dementia and Alzheimer's disease [17]. Ca was a preferable addition element for its capability of refining microstructure and biomimetic mineralization behavior during alloy biodegradable process [18]; $\mathrm{Zn}$ is next to aluminum in strengthening effectiveness as an alloying element in $\mathrm{Mg}$, and adding $\mathrm{Zn}$ can improve both the tensile strength and the corrosion resistance of $\mathrm{Mg}$ alloys 
[19]. In vitro cytotoxicity assessments indicated that $\mathrm{Mg}-\mathrm{Zn}$ Ca alloys did not induce toxicity in L-929 cells and are suitable for biomedical applications [20].

Surface treatment considered in previous studies includes chemical conversion coatings [21-23], electrochemical plating [24], anodizing [25], microarc [26], polymer coatings [27], and sol-gel coatings [28]. Among all the treatment methods, phosphate conversion coating was easier to acquire and more environmentally friendly. Phosphate conversion coating consists of crystalline or amorphous surface metal phosphates or of metal phosphate ions in the passivating solution and is usually carried out by immersion of the metal samples into the phosphating baths at a certain range of bath temperature and $\mathrm{pH}$ value of the bath solution $[29,30]$. Besides, when phosphate coating is used as a pretreatment layer between the substrate and a top layer, the pores in the coating may improve the bonding ability between substrate and top coating [31]. Calcium phosphate $(\mathrm{CaP})$ coatings enhance cellular adhesion, proliferation, and differentiation to promote bone regeneration [22, 32-35]. Studies also referred to the fact that increase of calcium phosphate could maintain homeostasis and reduce the level of $\mathrm{pH}$ in physiological system [36]. Manganese-containing coatings induced higher bone-related gene expression in a culture of osteoblastic cells. This indicates that manganese could improve cell mediated mineralization [37]. CaP coating was reported in our previous work and coatings containing $\mathrm{Mn}$ element were reported in studies elsewhere that contributed to corrosion resistance on $\mathrm{Mg}$ alloys [24, 38-40].

Calcium can significantly influence the stability of $\mathrm{Mg}$ Zn alloy, the crystallization of alloy can be refined [41], and a precipitate that has a complex structure can form. The precipitation has good high temperature stability, which can significantly improve the creep resistance of $\mathrm{Mg}$ alloy. The addition of trace amounts of Ca can have a substantial positive influence on the precipitation, process during artificial ageing in the Mg-Zn system [41]. The microstructure of the modified alloy is more complex and has a much refined precipitate structure that is very stable for prolonged periods, leading to a significant improvement in creep resistance. $\mathrm{Mg}-5 \mathrm{Zn}-1.5 \mathrm{Ca}$ alloy was found to be nontoxic and have good mechanical properties (the comparison is in another unpublished article of our study); thus $\mathrm{Mg}-5 \mathrm{Zn}-1.5 \mathrm{Ca}$ alloy was applied as $\mathrm{Mg}$ matrix substrate in this study.

The aim of this study was to develop a manganesecalcium phosphate conversion coating on $\mathrm{Mg}-5 \mathrm{Zn}-1.5 \mathrm{Ca}$ alloy which only employed $\mathrm{MnCl}_{2}$ and $\mathrm{Ca}\left(\mathrm{NO}_{3}\right)_{2}$ as the essential precursors that further improve the corrosion resistance property. Effect of $\mathrm{Mn}$ addition's amount in the phosphate solution to the coating's corrosion resistance was investigated; the in vitro biodegradation behavior and hydrogen evolution in SBF were evaluated. The morphology and composition of the coatings were also examined by X-ray diffraction (XRD) and scanning electron microscope (SEM) with energy dispersion spectroscopy (EDS). Furthermore, we also analyzed the polarization measurement, degradation behavior, impedance, and anticorrosion ability of a conversion coating on the $\mathrm{Mg}$ alloy.

\section{Materials and Methods}

2.1. Sample Preparation and Coating Process. In this work, a home-made extruded $\mathrm{Mg}-5 \mathrm{Zn}-1.5 \mathrm{Ca}$ alloy with a dimension of $10 \mathrm{~mm} \times 10 \mathrm{~mm} \times 5 \mathrm{~mm}$ and compositions of $5 \mathrm{wt} \% \mathrm{Zn}$, $1.5 \mathrm{wt} \% \mathrm{Ca}$, and $\mathrm{Mg}$ balance was used as the substrate material in the following coating processes. Firstly, the samples were subsequently abraded by 500, 1000, 1500, and 2000 grit sandpapers to remove the oxide layer and to obtain similar surface roughness not more than RA 0.05 (the phosphate coatings would be uneven if the surface roughness of the $\mathrm{Mg}$ alloy substrate is high) and then ultrasonically rinsed in ethanol in order to remove grease on the alloy surface. For comparison purpose, 3 sets of samples were prepared and tested, respectively, and the average values were calculated. In this study, a "calcium salts pretreatment and phosphate coating" phosphate process was introduced to prepare phosphate coatings. The purpose of calcium salts pretreatment was to form denser and homogenous calcium activated particle on the sample surface which contributes to the uniform and complete phosphate coatings.

Samples were pretreated in a calcium solution with $1.1 \mathrm{~mol} / \mathrm{L} \mathrm{CaO}$ and $0.20 \mathrm{~mol} / \mathrm{L} \mathrm{HNO} 3$ liquor for 0.5 minutes at $\mathrm{pH}$ 1.8. Then the samples were rinsed with deionized water and were coated in the phosphate solution for 10 minutes under $37^{\circ} \mathrm{C}$ at $\mathrm{pH}$ 2.7. The composition of phosphate solution was listed in Table 1 . The $\mathrm{pH}$ of the phosphating solution was adjusted using nitric acid (HNO3) or sodium hydroxide $(\mathrm{NaOH})$. All the chemical reagents were of reagent grade and purchased from Sinopharm Chemical Reagent Co. (Shanghai, China).

2.2. Analysis of Composition of Phosphate Coating and Morphology Analysis. The phases of the coatings were analyzed by a X-ray diffractometer (XRD, Rigaku Dymax, Japan) with a $\mathrm{Cu} \mathrm{K} \alpha$ radiation $(\gamma=0.154178 \mathrm{~nm})$ and a monochromator at $40 \mathrm{kV}$ and $100 \mathrm{~mA}$ with the scanning rate and step being $4^{\circ} / \mathrm{min}$ and $0.02^{\circ}$, respectively. The surface morphologies of the samples were examined using a JSM-5310 scanning electron microscope (SEM, ZEISS EV018, Germany), with the voltage of $20 \mathrm{kV}$ and working distance (WD) of $10.0 \mathrm{~mm}$. The surface chemical elements were analyzed using an attached INC250 energy dispersive X-ray analyzer (EDS, X-Max, Oxford Instruments, UK) with the acquisition duration of $60 \mathrm{~s}$.

The surface morphologies of the samples were examined using a JSM-5310 scanning electron microscope (SEM, ZEISS EV018, Germany; WD $=12.0, \mathrm{EHT}=20 \mathrm{kV})$. After performing immersion test in SBF for 168 hours, the surface morphologies of the samples were characterized and analyzed.

2.3. Potentiodynamic Polarization. The electrochemical measurements were performed by using a potentiostat (VersaSTAT 3, Princeton Applied Research, US) with a threeelectrode system. In this system, a platinum electrode was treated as the counter electrode, and a saturated calomel electrode (SCE, $+0.242 \mathrm{~V}$ versus $\mathrm{SHE}$ ) was regarded as the reference electrode, while the sample with an exposed area of $1 \mathrm{~cm}^{2}$ was regarded as the working electrode. Prior to 
TABLE 1: Composition of solutions and Mn content in the coatings of samples.

\begin{tabular}{lcc}
\hline & Composition of phosphating solution $(\mathrm{mol} / \mathrm{L})$ & Mn content in phosphating coating (EDS in Figure 3) (wt\%) \\
\hline Sample 1 & Base solution & 0 \\
Sample 2 & Base solution with $0.01 \mathrm{~mol} / \mathrm{L} \mathrm{Mn}^{2+}$ & $0.13 \%$ \\
Sample 3 & Base solution with $0.03 \mathrm{~mol} / \mathrm{L} \mathrm{Mn}^{2+}$ & $0.96 \%$ \\
Sample 4 & Base solution with $0.05 \mathrm{~mol} / \mathrm{L} \mathrm{Mn}^{2+}$ & $13.83 \%$ \\
Sample 5 & Base solution with $0.07 \mathrm{~mol} / \mathrm{L} \mathrm{Mn}^{2+}$ & $14.16 \%$ \\
\hline
\end{tabular}

${ }^{* *}$ Composition of base solution: $0.26 \mathrm{~mol} / \mathrm{L} \mathrm{CaNO}_{3} \cdot 4 \mathrm{H}_{2} \mathrm{O}, 0.17 \mathrm{~mol} / \mathrm{L} \mathrm{H}_{3} \mathrm{PO}_{4}$ aqueous solution at $\mathrm{pH} 2.7$.

performing the measurements, the samples were immersed in the SBF solution for about 30 min to establish an open circuit potential (OCP) for making the system stable firstly.

\subsection{Electrochemical Impedance Spectroscopy. The corrosion} resistance and biodegradable property of the coatings were evaluated by the electrochemical measurements and immersion tests in the $\mathrm{SBF}$ solution $\left(37^{\circ} \mathrm{C}\right)$. The $\mathrm{SBF}$ solution is composed of $8.0 \mathrm{~g} / \mathrm{L} \mathrm{NaCl}, 0.4 \mathrm{~g} / \mathrm{L} \mathrm{KCl}, 0.14 \mathrm{~g} / \mathrm{L} \mathrm{CaCl} 2,0.35 \mathrm{~g} / \mathrm{L}$ $\mathrm{NaHCO}_{3}, 1.0 \mathrm{~g} / \mathrm{L} \mathrm{C}_{6} \mathrm{H}_{12} \mathrm{O}_{6}$ (glucose), $0.2 \mathrm{~g} / \mathrm{L} \mathrm{MgSO}_{4} \cdot \mathrm{H}_{2} \mathrm{O}$, $0.1 \mathrm{~g} / \mathrm{L} \mathrm{KH} \mathrm{KO}_{4} \cdot \mathrm{H}_{2} \mathrm{O}$, and $0.06 \mathrm{~g} / \mathrm{L} \mathrm{Na}_{2} \mathrm{HPO}_{4} \cdot \mathrm{H}_{2} \mathrm{O}$ and $\mathrm{pH}$ $=7.4$ [42]. The impedances of the samples were evaluated by the electrochemical impedance spectroscopy (EIS) analysis at an OCP of $10 \mathrm{mV}$ from $100 \mathrm{kHz}$ down to $10 \mathrm{MHz}$ additionally; the potentiodynamic polarization test proceeded at a scanning rate of $5 \mathrm{mV} / \mathrm{s}$ and in the range of $\mathrm{OCP} \pm 1.5 \mathrm{~V}$. The data curves of the tested samples for the potentiodynamic polarization and EIS experiments were analyzed through CorrView and ZSimpWin software, respectively.

2.5. Test of Hydrogen Evolution. All the samples were immersed in the SBF solution at $37^{\circ} \mathrm{C}$ for 168 hours for analyzing the corrosion behaviors of coatings on $\mathrm{Mg}$ alloys. The hydrogen evolution volumes of the samples in the SBF solutions were recorded every 12 hours. Three sets of samples were prepared and tested, respectively. All the tests in this paper have been repeated at least three times and five times for the data with obvious errors.

\section{Results and Discussion}

3.1. Phosphate Coating with the Calcium Salts Pretreatment Film. The preparation of samples was shown in Materials and Methods. Mg-5Zn-1.5Ca alloy pieces, after removing all of the oxide film, were treated by calcium salt treatment in the pretreatment solution. All of the samples were pretreated in the same solution: $1.2 \mathrm{~mol} / \mathrm{L} \mathrm{CaO}$ and $0.21 \mathrm{~mol} / \mathrm{L} \mathrm{HNO}_{3}$ at $\mathrm{pH}$ 1.8. SEM images of the composition of calcium salts pretreatment solution of the film are shown in Figure 1. After water rinse, samples were coated with phosphate coating in different solution; their chemical components are shown in Table 1. The manganese content in the phosphate coating was obtained by EDS. The details of the other elements of EDS are listed in Figure 3.

In Table 1, the manganese content in the phosphate coating obtained from solution containing $0.03 \mathrm{~mol} / \mathrm{L} \mathrm{Mn}^{2+}$ was less $(0.96 \%)$. The manganese content in the phosphate coating

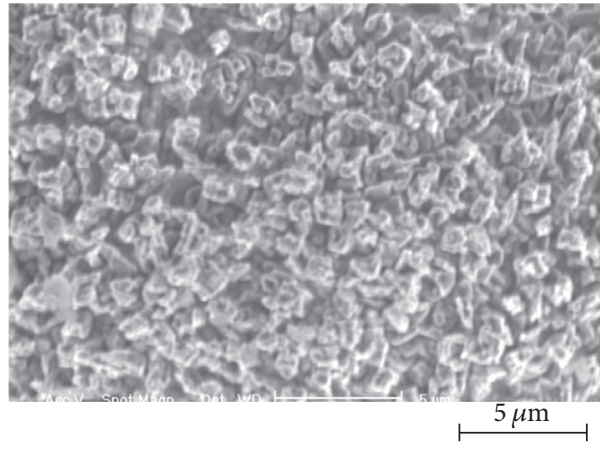

FIGURE 1: SEM of the calcium pretreatment film on the Mg alloy.

obtained from solution containing $0.05 \mathrm{~mol} / \mathrm{L} \mathrm{Mn}^{2+}$ was up to $13.83 \%$. The manganese content of phosphate coatings was increased with the $\mathrm{Mn}^{2+}$ addition in the phosphating solution.

Figure 1 showed SEM image of the calcium pretreatment film on the Mg-5Zn-1.5Ca alloy. After pretreatment, it can be seen that a base film with uniform and dense microstructure formed on the substrate. The pretreatment film was not sufficient to fully cover the $\mathrm{Mg}$ alloy substrate, but the small crystal nucleus provided a rough surface to promote the formation of the later phosphate conversion coatings and offered basic protection for the $\mathrm{Mg}$ alloy.

Figure 2 illustrated the XRD patterns phosphate coatings with various $\mathrm{Mn}^{2+}$ contents on $\mathrm{Mg}-5 \mathrm{Zn}-1.5 \mathrm{Ca}$ alloy substrates. Dicalcium dihydrate (DCPD, $\left.\mathrm{CaHPO}_{4} \cdot 2 \mathrm{H}_{2} \mathrm{O}\right)$ and $\mathrm{Ca}_{2} \mathrm{Mg}_{6} \mathrm{Zn}_{3}$ were detected in CaP coating in Sample 1, and DCPD and $\mathrm{Ca}_{2} \mathrm{Mg}_{6} \mathrm{Zn}_{3}$ characteristic peaks remained in the phosphate coatings, but their peaks' intensity became weak in Sample 4, and they were rarely observed in Sample 5. A small quantity of tricalcium phosphate (TCP, $\left.\mathrm{Ca}_{3}\left(\mathrm{PO}_{4}\right)_{2}\right)$ that was often reported to appear in CaP coatings [27, 43] was also detected in all of the coatings. In coating of Sample 2, $0.01 \mathrm{~mol} / \mathrm{L} \mathrm{Mn}^{2+}$ was added to the phosphate coating, and manganese hydrogen phosphate trihydrate (MHPT, $\mathrm{MnHPO}_{4} \cdot 3 \mathrm{H}_{2} \mathrm{O}$ ) can be weakly detected, and its diffraction peak intensity increased with the increase of the $\mathrm{Mn}^{2+}$ addition in phosphate coating solution of Sample 3, Sample 4 , and Sample 5.

3.2. Microstructure of Phosphate Coatings before Immersed Test. The SEM surface morphology of coatings on samples was shown in Figure 3. Along with the gradual increase 


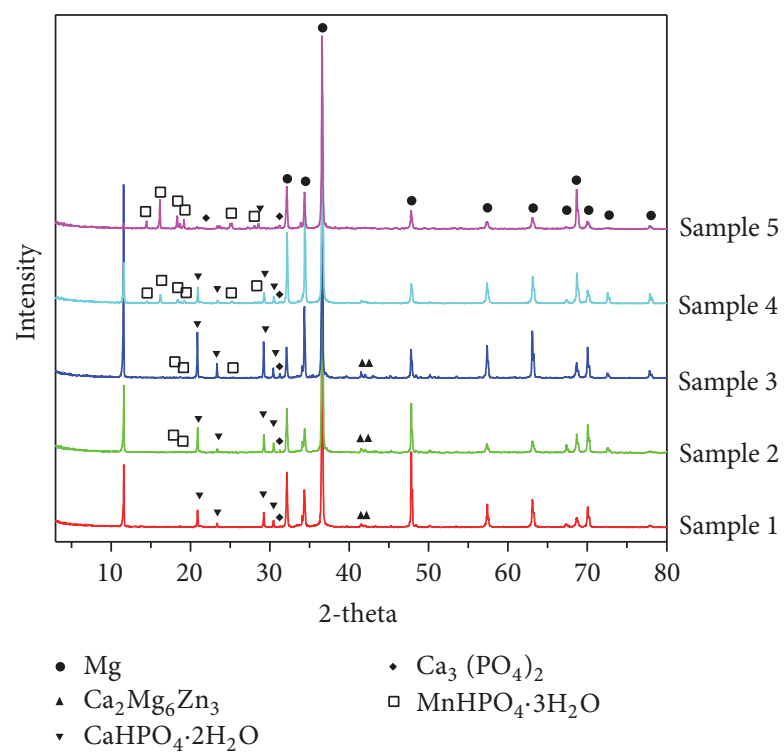

FIGURE 2: XRD analysis of phosphate coatings on samples.

of $\mathrm{Mn}^{2+}$ content, the morphologies of the coatings show an obvious trend of variation. In all of the figures, the scattered flakes reduced on the surface morphology of samples and lumpy crystals started to appear. The flakes have been reported in researches as a typical $\mathrm{CaP}$ coating morphology, and the lumpy crystals could be considered a typical $\mathrm{MnHPO}_{4}$ structure as reported in studies of manganese phosphate coatings on $\mathrm{Mg}$ alloy [44]. As revealed in Figure 3(a), the surface of a CaP coating was uniform and dense, while the size of a flake approximated $10 \mu \mathrm{m}$. From Figure 3(b), the coating of Sample 2 had smaller flakes than a $\mathrm{CaP}$ coating and some crystals appear. In Figures 3(c), 3(d), and $3(\mathrm{e})$, the number of crystals $\left(\mathrm{MnHPO}_{4} \cdot 3 \mathrm{H}_{2} \mathrm{O}\right)$ increased and flakes $\left(\mathrm{Ca}_{3}\left(\mathrm{PO}_{4}\right)_{2}\right.$ and $\left.\mathrm{CaHPO}_{4} \cdot 2 \mathrm{H}_{2} \mathrm{O}\right)$ decreased with the $\mathrm{Mn}$ amount increase. Especially in Figure 3(d), the flakes and crystals densely alternate with each other, so that the coating of Sample 4 can offer good protection for $\mathrm{Mg}$ alloy. Furthermore, most of the flakes disappeared and many crystals were cracked in Figure 3(e) for Sample 5. Obviously, the high amounts of $\mathrm{Mn}^{2+}$ additive make coatings containing $\mathrm{Mn}^{2+}$ appear to be of crystal-like structure, which probably consists of the $\mathrm{MnHPO}_{4} \cdot 3 \mathrm{H}_{2} \mathrm{O}$ and was clearly detected by the XRD tests of Sample 4 and Sample 5, as shown in Figure 2.

\subsection{Electrochemical Corrosion Behavior of the Samples.} Potentiodynamic polarization curves and their corresponding electrochemical parameters of the samples were shown in Figure 4 and Table 2, respectively. Figure 4 showed the corrosion potential $\left(E_{\text {corr }}\right)$ and corrosion current densities $\left(i_{\text {corr }}\right)$ of phosphate coatings. Samples with more positive $E_{\text {corr }}$ would have greater potential of corrosion. As shown in Table 2, $E_{\text {corr }}$ of Sample 1 and Sample 2 was more positive and $E_{\text {corr }}$ of Sample 4 was the least positive and was $204 \mathrm{mV} / \mathrm{SCE}$ more negative than Sample 1. Thus, it can be deducted that, in the corrosion process, Sample 4 tended less to be corroded. $i_{\text {corr }}$ was in direct proportion to corrosion rate; $i_{\text {corr }}$ of Sample
TABLE 2: Electrochemical parameters corresponding to the polarization curves in Figure 5.

\begin{tabular}{lcc}
\hline Samples & $\begin{array}{c}E_{\text {corr }} \\
(\mathrm{mV} / \mathrm{SCE})\end{array}$ & $\begin{array}{c}I_{\text {corr }} \\
\left(\mathrm{A} / \mathrm{cm}^{2}\right)\end{array}$ \\
\hline Sample 1 & -1529 & $3.548 \times 10^{-5}$ \\
Sample 2 & -1468 & $2.023 \times 10^{-5}$ \\
Sample 3 & -1387 & $5.400 \times 10^{-5}$ \\
Sample 4 & -1305 & $7.414 \times 10^{-7}$ \\
Sample 5 & -1325 & $9.063 \times 10^{-5}$ \\
\hline
\end{tabular}

4 was the lowest and was $0.036 \%-0.081 \%$ of other samples. As a result, Sample 4 had better anticorrosion performance and could prevent decompositions.

For further evaluation on the corrosion behaviors of the coatings, the EIS test was employed. Figure 5 and Table 3 show the Nyquist plots and the main fitting results for the coated samples, respectively. The equivalent circuits and detailed description for the Nyquist plot in this study were similar to those in our prior research [45]. The Nyquist plot for coatings of Samples 1, 2, and 3 contained one high frequency (HF) capacitive loop and one medium frequency (MF) capacitive loop. This diagram was analyzed using the equivalent circuit in Figure 6(a), which reveals the presence of different intersurface areas with different characteristics. The HF capacitive loop was related to the dielectric properties of the coating (characterized by $R_{c}$ and $Q_{c}$ ), and $R_{\mathrm{ct}}$ was the charge transfer resistance. The second equivalent circuit shown in Figure 6(b) was used to describe the Nyquist plots for coatings of Sample 4 and Sample 5. The plots only contained one capacitance loop, which refers to the simple process at the solution/coating interface and implies that the coatings have full coverage and could supply good corrosion protection for the substrate $\mathrm{Mg}$ alloy. $C_{\mathrm{dl}}$ represents the electric double layer capacity at the solution/substrate interface at pinholes [1]. As compared to the base solution coated samples, the solution containing $\mathrm{Mn}^{2+}$ coated samples had smaller $C_{\mathrm{dl}}$ values, especially for the Sample 4 coated one. This implies that the coating of Sample 4 has denser surface structures than other coatings. The total surface resistance $\left(R_{\text {total }}\right)$ of the coating of Sample 4 was $36273 \Omega \mathrm{cm}^{2}$, which was 11.5 times $R_{\text {total }}$ of the coating of Sample 1. Thus, either the potentiodynamic polarization or the EIS test indicates that the coating of Sample 4 on a Mg-5Zn-1.5Ca alloy possesses better anticorrosion ability than other coatings in this study.

3.4. Corrosion Behaviors of the Samples in Immersion Tests. The SEM photos for the surface morphologies of the samples after being corroded by the SBF solution for 168 hours are shown in Figure 7. After being immersed in the SBF solution, the flake-like coating of Sample 1 and Sample 2 was undistinguishable, cracked, and covered by corrosion products as illustrated in Figures 7(a) and 7(b). During the immersion process, the second phase particles Ca2Mg6Zn3 acted as cathodes and caused the dissolution of the coating and the exposure of the $\mathrm{Mg}$ alloy substrate. On the surface of Sample 3 in Figure 7(c), the flakes were still observable 


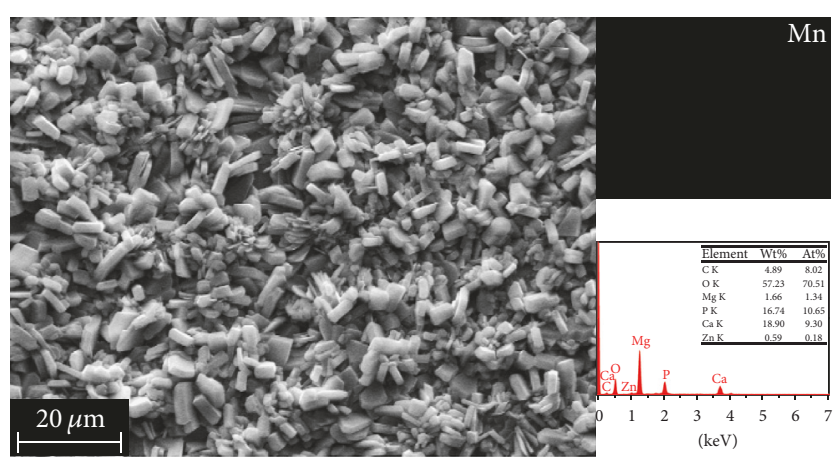

(a)

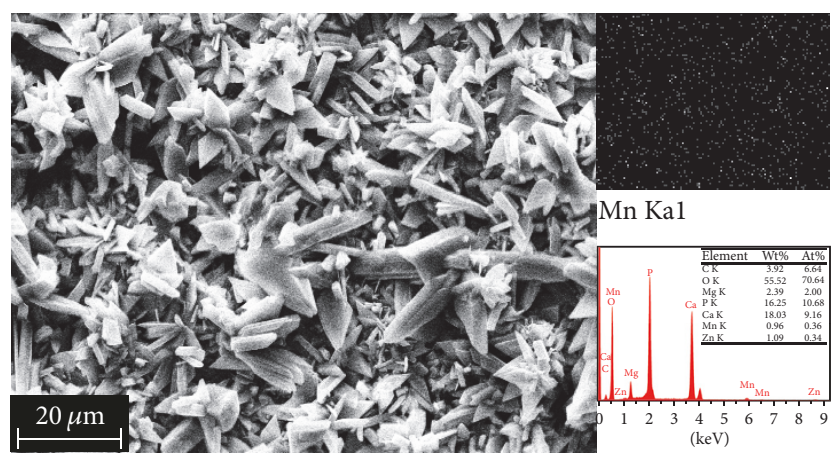

(c)

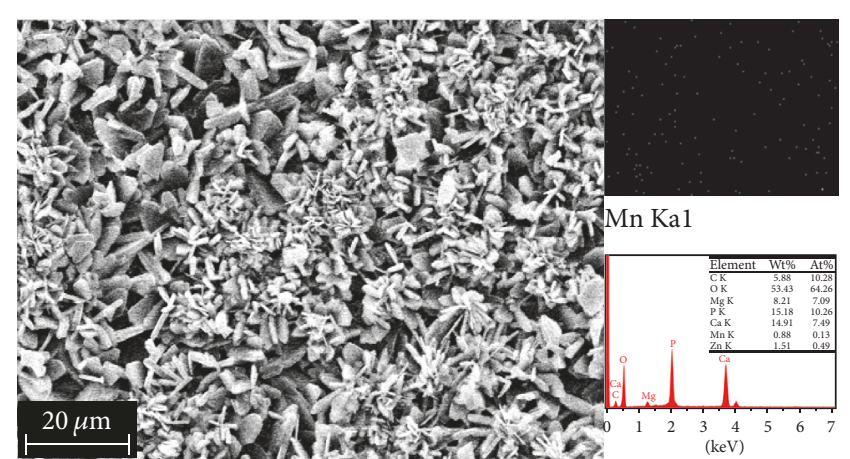

(b)

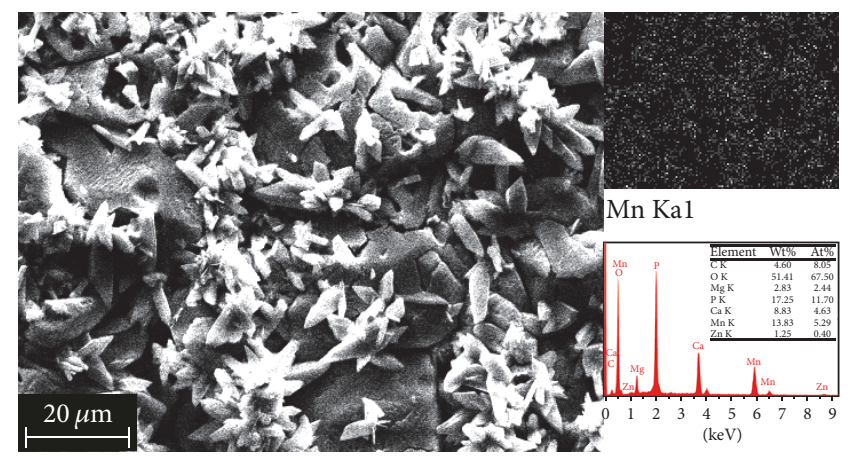

(d)

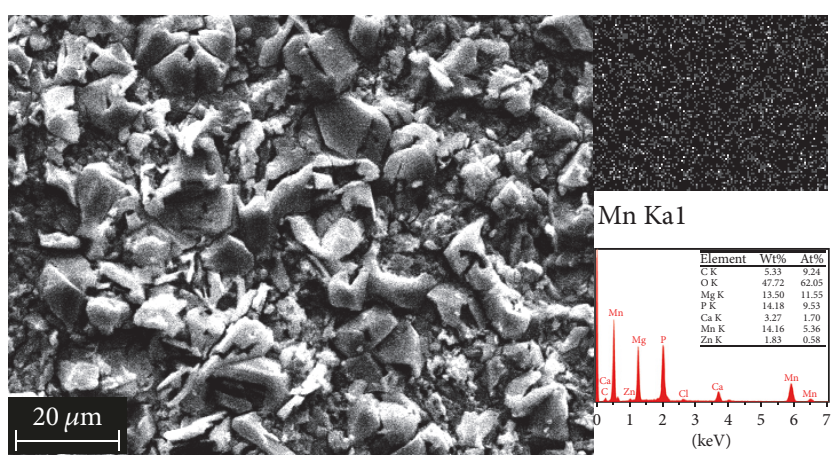

(e)

FIGURE 3: SEM surface morphology (a)-(e): phosphate coating obtained from calcium phosphating solution containing $0,0.01,0.03,0.05$, and $0.07 \mathrm{~mol} / \mathrm{L} \mathrm{Mn}^{2+}$ content on Samples 1-5.

and they cover most of the cracks so as to provide a better protection for the Mg alloy. The coating of Sample 4 as shown in Figure $7(\mathrm{~d})$ is intact and almost free of pitting corrosion. The three components $\mathrm{CaHPO} 4 \cdot 2 \mathrm{H} 2 \mathrm{O}, \mathrm{Ca} 3$ (PO4)2, and $\mathrm{MnHPO} 4 \cdot 3 \mathrm{H} 2 \mathrm{O}$ were homogenized in the coating, which may cause the change of corrosion mechanism from local corrosion to uniform corrosion. This indicates that the lumpycrystal manganese compound offered a most improved corrosion protection for the $\mathrm{Mg}$ alloy. However, a small amount of corrosion cracking occurs in Figure $7(\mathrm{e})$ with the further increasing Mn content. The content of $\mathrm{MnHPO} 4 \cdot 3 \mathrm{H} 2 \mathrm{O}$ in the $\mathrm{XRD}$ analysis in Figure 2 showed that the concentration of MnHPO4 $\cdot 3 \mathrm{H} 2 \mathrm{O}$ was the highest. This is possibly caused by the stress corrosion of the lumpy coating in the simulated body fluid. Therefore, these phenomena indicate that the coating of Sample 4 provided a complemented structure that would protect $\mathrm{Mg}$ alloy durably.

Analysis from Figure 7 and the XRD results in Figure 2 can be made as follows:

(1) The second phase particles $\mathrm{Ca}_{2} \mathrm{Mg}_{6} \mathrm{Zn}_{3}$ containing $\mathrm{Ca}$ and $\mathrm{Zn}$ are used as cathodes in the film layer which caused the anode of the film to dissolve and the $\mathrm{Mg}$ alloy matrix was exposed. Therefore, the corrosion is more severe (11.25 wt\% Mg exposed) in Figure 7(a).

(2) Corrosion cracking also is shown in Figure 7(b) and Figure $7(\mathrm{c})$. This was because $\mathrm{CaHPO}_{4} \cdot 2 \mathrm{H}_{2} \mathrm{O}$ in the film contained a large amount of active element $\mathrm{Ca}$. This caused dissolution corrosion, which can be seen from the calcium contents of 14.91 and $18.03 \mathrm{wt} \%$ 
TABLE 3: Main fitting results of Nyquist plot exhibited in Figure 6.

\begin{tabular}{lcccccc}
\hline Samples & $\begin{array}{c}\mathrm{Rc} \\
\left(\Omega \mathrm{cm}^{2}\right)\end{array}$ & $\begin{array}{c}\mathrm{Cdl} \\
\left.(\mu \mathrm{Fcm})^{-2}\right)\end{array}$ & $\begin{array}{c}\text { Rct (Rmt) } \\
\left(\Omega \mathrm{cm}^{2}\right)\end{array}$ & $\begin{array}{c}\text { Rads } \\
\left(\Omega \mathrm{cm}^{2}\right)\end{array}$ & $\begin{array}{c}\text { Lads } \\
\left(\mathrm{Hcm}^{-2}\right)\end{array}$ & $\begin{array}{c}\text { Rtotal } \\
\left(\Omega \mathrm{cm}^{2}\right)\end{array}$ \\
\hline Sample 1 & 2223 & 118 & 928 & - & - & - \\
Sample 2 & 448 & 13 & 3572 & - & - & - \\
Sample 3 & 1400 & 4 & 17030 & - & - & -1020 \\
Sample 4 & 1843 & 1.3 & 34430 & - & - & 36273 \\
Sample 5 & 287 & 5 & 1138 & & - \\
\hline
\end{tabular}

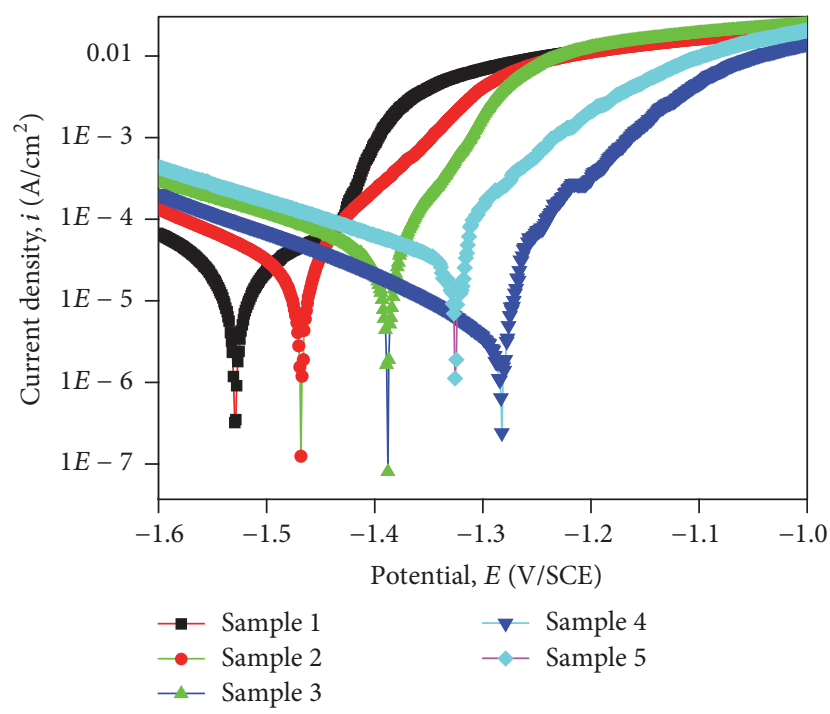

FIGURE 4: The polarization curves of coatings on Samples 1-5 in SBF solution.

in map scanning results of Figures $7(\mathrm{~b})$ and $7(\mathrm{c})$, respectively.

(3) The film layer in Figure $7(\mathrm{~d})$ was intact and free of corrosion. $\mathrm{CaHPO}_{4} \cdot 2 \mathrm{H}_{2} \mathrm{O}, \mathrm{Ca}_{3}\left(\mathrm{PO}_{4}\right)_{2}$, and $\mathrm{MnHPO}_{4} \cdot 3 \mathrm{H}_{2} \mathrm{O}$ homogenized the film, the corrosion current was evenly dispersed, and the film was more resistant to corrosion. The relative potential of these three components and the Mg alloy matrix changed, which is the cause of the change of local corrosion mechanism.

(4) A small amount of corrosion cracking is shown in Figure $7(\mathrm{e})$. The content of $\mathrm{MnHPO}_{4} \cdot 3 \mathrm{H}_{2} \mathrm{O}$ in the $\mathrm{XRD}$ analysis in Figure 2 showed that the concentration of $\mathrm{MnHPO}_{4} \cdot 3 \mathrm{H}_{2} \mathrm{O}$ was higher than that of the other four samples. Maybe when concentration of the higher hard $\mathrm{MnHPO}_{4} \cdot 3 \mathrm{H}_{2} \mathrm{O}$ in the coating surface is more than a certain value, stress corrosion crack is generated on the coating in the simulated body fluid. The mechanism would be further studied in our next work.

The samples were, respectively, immersed in the SBF solution for 168 hours, while the hydrogen $\left(\mathrm{H}_{2}\right)$ evolution volumes variation was shown Figure 8. Results in Figure 8 indicate that the $\mathrm{H}_{2}$ evolution volume of all the coatings

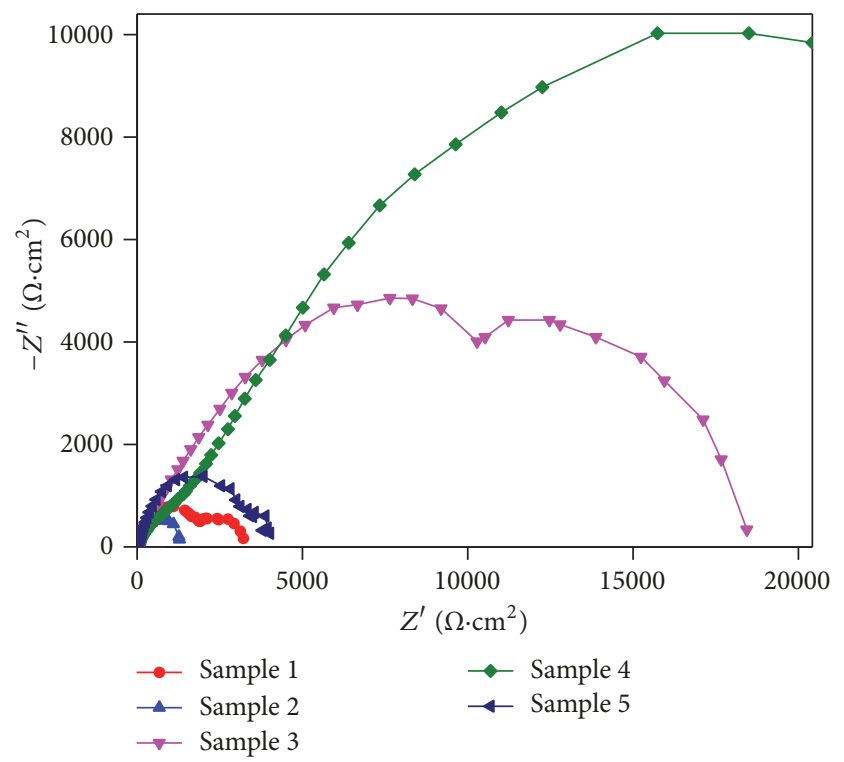

FIGURE 5: EIS patterns of coatings on Samples 1-5 in SBF solution.

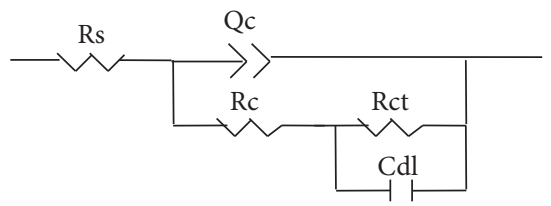

(a)

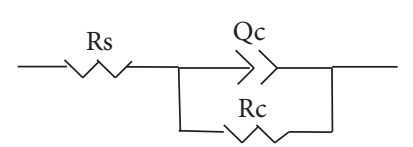

(b)

FIGURE 6: Equivalent circuits for EIS plots of (a) coatings of Samples 1,2 , and 3 and (b) coatings of Samples 4 and 5.

containing $\mathrm{Mn}^{2+}$ was relatively lower than that of the coating of Sample 1 in the SBF, which implies better anticorrosion reaction. Coating of Sample 4 had the lowest $\mathrm{H}_{2}$ evolution volume in this test, which remained almost $0 \mathrm{ml}$ for the first 96 hours and increased very slowly to $1.4 \mathrm{ml} / \mathrm{cm}^{2}$ measured at the 168th hour. Standard deviation in Figure 8 also demonstrates that $\mathrm{H}_{2}$ evolution volume of Sample 4 was more stable than that of other coatings. Hence, these results stated that the coating of Sample 4 had the promising property of 


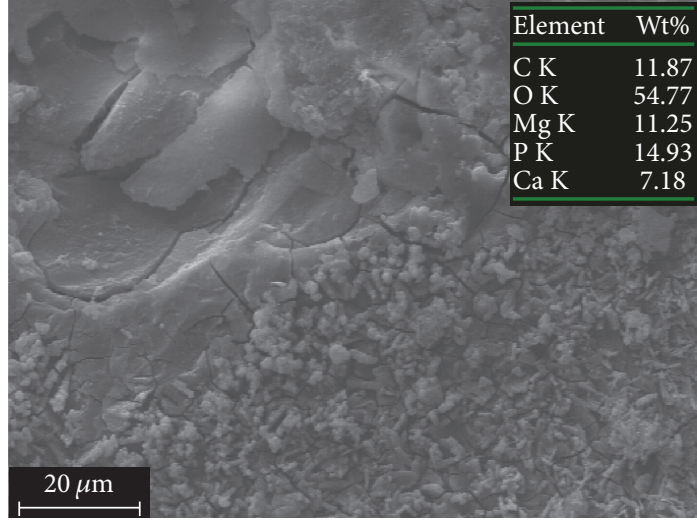

(a)

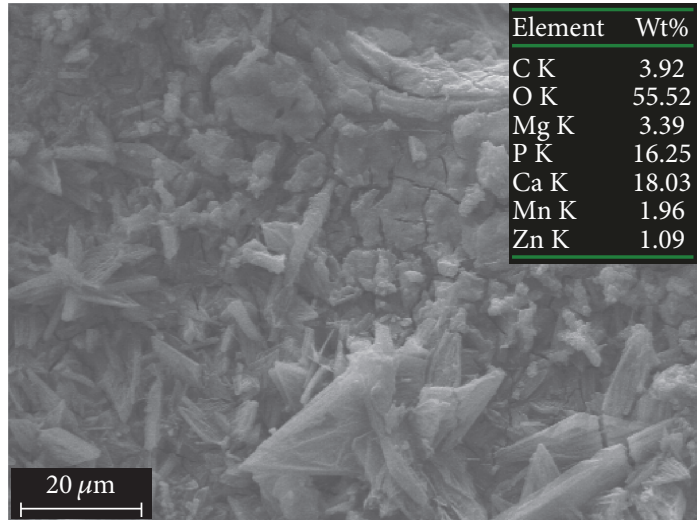

(c)

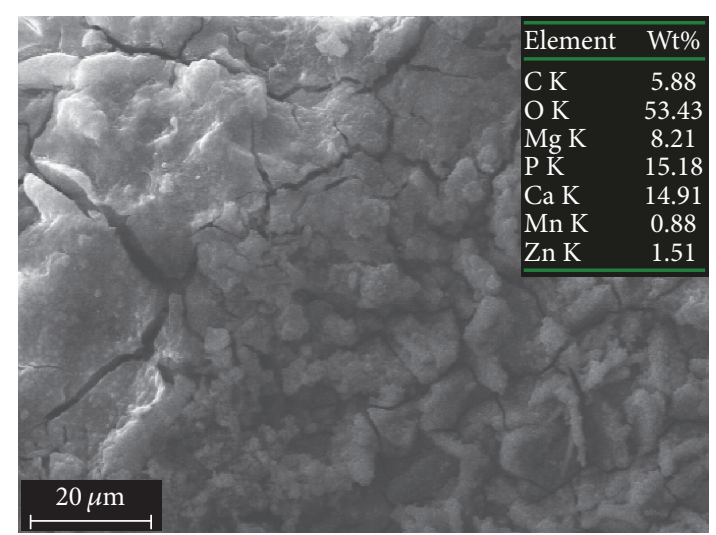

(b)

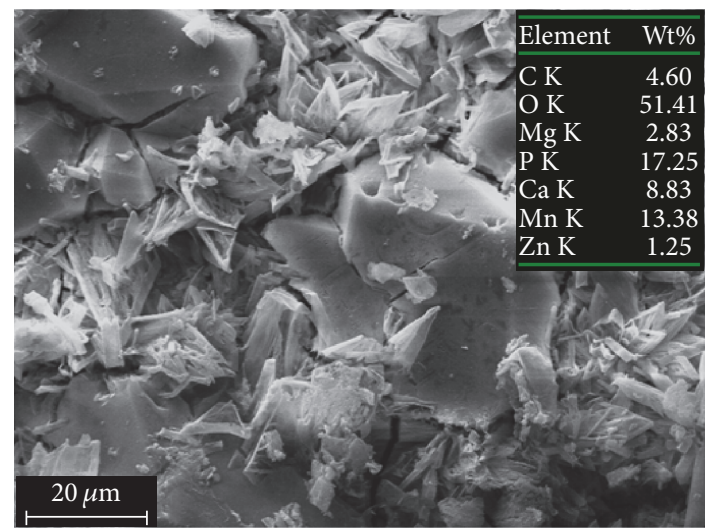

(d)

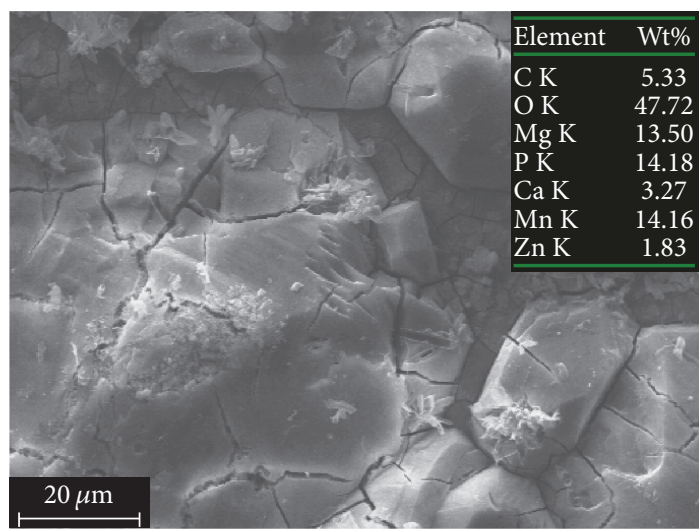

(e)

FIGURE 7: EDS and SEM of samples after being immersed in SBF for 168 hours: phosphate coating obtained from solution containing (a) $0 \mathrm{~mol} / \mathrm{L} \mathrm{Mn}^{2+}, 0.01 \mathrm{~mol} / \mathrm{L} \mathrm{Mn}^{2+}, 0.03 \mathrm{~mol} / \mathrm{L} \mathrm{Mn}^{2+}, 0.05 \mathrm{~mol} / \mathrm{L} \mathrm{Mn}^{2+}$, and $0.07 \mathrm{~mol} / \mathrm{L} \mathrm{Mn}^{2+}$.

lower $\mathrm{H}_{2}$ evolution volume applied on $\mathrm{Mg}$ alloy surface when served as body implant materials.

\section{Conclusions}

(1) Manganese-calcium phosphate coatings were prepared on an Mg-5Zn-1.5Ca alloy in calcium phosphating solutions with different addition of $\mathrm{Mn} 2+$. A calcium salt pretreatment film was applied to homogenize the subsequent manganese-calcium phosphate coating.

(2) Mn content in the phosphate coatings has significant influences on the coating morphology and degradation behavior. With the increasing Mn addition, the degradation resistance of the manganese-calcium phosphate coatings was gradually improved. 


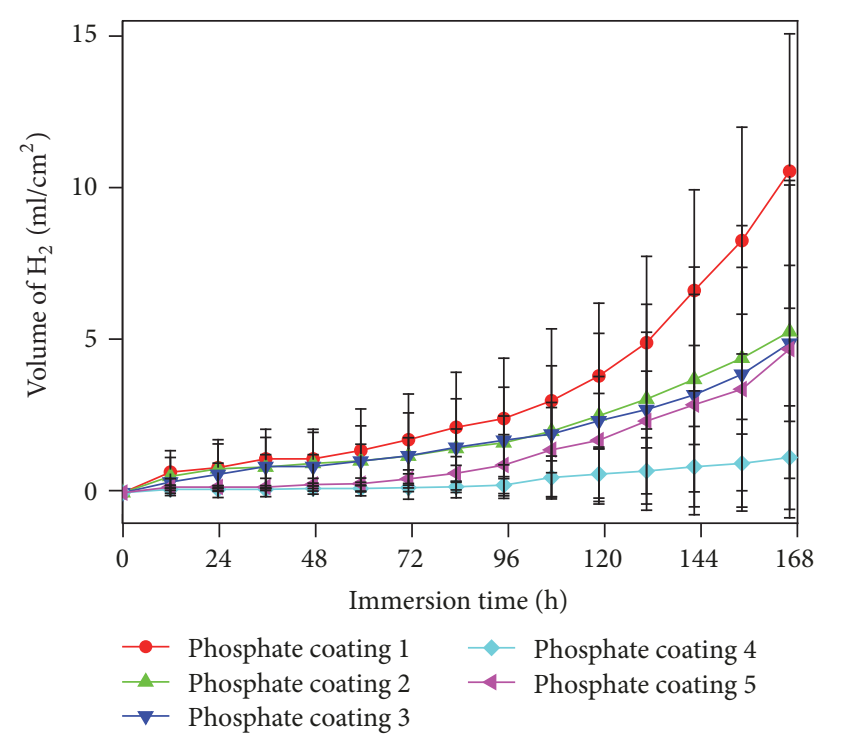

FIGURE 8: Hydrogen evolution volumes of coatings on Samples 1-5 in SBF solution for 168 hours.

(3) The optimum coating prepared in solution containing $0.05 \mathrm{~mol} / \mathrm{L} \mathrm{Mn} 2+$ had a uniform and compact microstructure and was composed of MnHPO4.3H2O, CaHPO4.2H2O, and Ca3(PO4)2. The electrochemical and immersion corrosion test in simulated body fluid revealed that the optimum coating had a greatly improved surface stability and degradation resistance compared to the calcium phosphate coating without Mn addition.

\section{Conflicts of Interest}

The authors declare no conflicts of interest.

\section{Authors' Contributions}

Yichang Su and Yingchao Su conceived and designed the experiments; Yichang Su and Wei Zai performed the experiments; Yichang Su analyzed the data and wrote the paper.

\section{Acknowledgments}

This work was supported by the National Natural Science Foundation of China (Grant nos. 31070841 and 51705195) and China Postdoctoral Science Foundation (Grant no. 801161082418).

\section{References}

[1] R. Radha and D. Sreekanth, "Insight of magnesium alloys and composites for orthopedic implant applications - a review," Journal of Magnesium and Alloys, vol. 5, no. 3, pp. 286-312, 2017.

[2] G. Song, "Control of biodegradation of biocompatable magnesium alloys," Corrosion Science, vol. 49, no. 4, pp. 1696-1701, 2007.
[3] B. Laycock, M. Nikolić, J. M. Colwell et al., "Lifetime prediction of biodegradable polymers," Progress in Polymer Science, vol. 71, pp. 144-189, 2017.

[4] G. Manivasagam and S. Suwas, "Biodegradable Mg and Mg based alloys for biomedical implants," Materials Science and Technology (United Kingdom), vol. 30, no. 5, pp. 515-520, 2014.

[5] A. Purnama, H. Hermawan, and D. Mantovani, "Biodegradable metal stents: A focused review on materials and clinical studies," Journal of Biomaterials and Tissue Engineering, vol. 4, no. 11, pp. 868-874, 2014.

[6] M. M. Saleh, M. M. Saleh, A. H. Touny, and M. A. Al-Omair, "Biodegradable/biocompatible coated metal implants for orthopedic applications," Bio-Medical Materials and Engineering, vol. 27, no. 1, pp. 87-99, 2016.

[7] Y. F. Zheng, X. N. Gu, and F. Witte, "Biodegradable metals," Materials Science and Engineering: R: Reports, vol. 77, pp. 1-34, 2014.

[8] S.-H. Chang, L. Niu, Y. Su, W. Wang, X. Tong, and G. Li, "Effect of the pretreatment of silicone penetrant on the performance of the chromium-free chemfilm coated on AZ91D magnesium alloys," Materials Chemistry and Physics, 2016.

[9] X.-B. Chen, N. Birbilis, and T. B. Abbott, "Effect of [Ca2+] and [PO43-] levels on the formation of calcium phosphate conversion coatings on die-cast magnesium alloy AZ91D," Corrosion Science, vol. 55, pp. 226-232, 2012.

[10] Z. Pu, G.-L. Song, S. Yang et al., "Grain refined and basal textured surface produced by burnishing for improved corrosion performance of AZ31B Mg alloy," Corrosion Science, vol. 57, pp. 192-201, 2012.

[11] N. Van Phuong and S. Moon, "Comparative corrosion study of zinc phosphate and magnesium phosphate conversion coatings on AZ31 Mg alloy," Materials Letters, vol. 122, pp. 341-344, 2014.

[12] Y. Su, L. Niu, Y. Lu, J. Lian, and G. Li, "Preparation and corrosion behavior of calcium phosphate and hydroxyapatite conversion coatings on AM60 magnesium alloy," Journal of The Electrochemical Society, vol. 160, no. 11, pp. C536-C546, 2013.

[13] A. Witecka, A. Bogucka, A. Yamamoto et al., "In vitro degradation of ZM21 magnesium alloy in simulated body fluids," Materials Science and Engineering C: Materials for Biological Applications, vol. 65, pp. 59-69, 2016.

[14] J. Li, P. Liu, C. Wu, and Y. Chen, "Common ion effect in the hydrolysis reaction of $\mathrm{Mg}$ [sbnd] Ca alloy hydride-salt composites," International Journal of Hydrogen Energy, vol. 42, no. 2, pp. 1429-1435, 2017.

[15] D. H. Cho, B. W. Lee, J. Y. Park, K. M. Cho, and I. M. Park, "Effect of $\mathrm{Mn}$ addition on corrosion properties of biodegradable $\mathrm{Mg}$ 4Zn-0.5Ca-xMn alloys," Journal of Alloys and Compounds, vol. 695, pp. 1166-1174, 2017.

[16] Y. Ding, Y. Li, J. Lin, and C. Wen, "Effects of zirconium and strontium on the biocorrosion of $\mathrm{Mg}$ - $\mathrm{Zr}$-Sr alloys for biodegradable implant applications," Journal of Materials Chemistry B, vol. 3, no. 18, pp. 3714-3729, 2015.

[17] J. Walker, S. Shadanbaz, T. B. F. Woodfield, M. P. Staiger, and G. J. Dias, "Magnesium biomaterials for orthopedic application: A review from a biological perspective," Journal of Biomedical Materials Research Part B: Applied Biomaterials, vol. 102, no. 6, pp. 1316-1331, 2014.

[18] N. Li and Y. Zheng, "Novel Magnesium Alloys Developed for Biomedical Application: A Review," Journal of Materials Science and Technology, vol. 29, no. 6, pp. 489-502, 2013. 
[19] E. Zhang, D. Yin, L. Xu, L. Yang, and K. Yang, "Microstructure, mechanical and corrosion properties and biocompatibility of Mg-Zn-Mn alloys for biomedical application," Materials Science Engineering C-Biomimetic and Supramolecular Systems, vol. 29, pp. 987-993, 2009.

[20] B. Zhang, Y. Hou, X. Wang, Y. Wang, and L. Geng, "Mechanical properties, degradation performance and cytotoxicity of $\mathrm{Mg}$ Zn-Ca biomedical alloys with different compositions," Materials Science and Engineering C: Materials for Biological Applications, vol. 31, no. 8, pp. 1667-1673, 2011.

[21] C. S. Lin, C. Y. Lee, W. C. Li, Y. S. Chen, and G. N. Fang, "Formation of phosphate/permanganate conversion coating on AZ31 magnesium alloy," Journal of The Electrochemical Society, vol. 153, no. 3, pp. B90-B96, 2006.

[22] Y. Su, C. Luo, Z. Zhang, H. Hermawan, and D. Zhu, "Bioinspired surface functionalization of metallic biomaterials," Journal of the Mechanical Behavior of Biomedical Materials, 2017.

[23] W. Zhou, D. Shan, E.-H. Han, and W. Ke, "Structure and formation mechanism of phosphate conversion coating on diecast AZ91D magnesium alloy," Corrosion Science, vol. 50, no. 2, pp. 329-337, 2008.

[24] X.-B. Chen, X. Zhou, T. B. Abbott, M. A. Easton, and N. Birbilis, "Double-layered manganese phosphate conversion coating on magnesium alloy AZ91D: Insights into coating formation, growth and corrosion resistance," Surface and Coatings Technology, vol. 217, pp. 147-155, 2013.

[25] Y. Zhang, Y. Ma, M. Chen, and J. Wei, "Effects of anodizing biodegradable $\mathrm{Mg}-\mathrm{Zn}-\mathrm{Zr}$ alloy on the deposition of $\mathrm{Ca}-\mathrm{P}$ coating," Surface and Coatings Technology, vol. 228, no. 1, pp. S111-S115, 2013.

[26] Y. K. Pan, C. Z. Chen, D. G. Wang, and T. G. Zhao, "Effects of phosphates on microstructure and bioactivity of micro-arc oxidized calcium phosphate coatings on $\mathrm{Mg}-\mathrm{Zn}-\mathrm{Zr}$ magnesium alloy," Colloids and Surfaces B: Biointerfaces, vol. 109, pp. 1-9, 2013.

[27] K. Kusnierczyk and M. Basista, "Recent advances in research on magnesium alloys and magnesium-calcium phosphate composites as biodegradable implant materials," Journal of Biomaterials Applications, vol. 31, no. 6, pp. 878-900, 2017.

[28] N. V. Murillo-Gutiérrez, F. Ansart, J.-P. Bonino, M.-J. Menu, and M. Gressier, "Protection against corrosion of magnesium alloys with both conversion layer and sol-gel coating," Surface and Coatings Technology, vol. 232, pp. 606-615, 2013.

[29] B. Liu, X. Zhang, G.-Y. Xiao, and Y.-P. Lu, "Phosphate chemical conversion coatings on metallic substrates for biomedical application: A review," Materials Science and Engineering C: Materials for Biological Applications, vol. 47, pp. 97-104, 2015.

[30] L. Tammy and R. L. P. A. Metroke, "Passivation of metal alloys using sol - gel-derived materials - a review," Progress in Organic Coatings, vol. 41, pp. 233-238, 2001.

[31] D. Weng, P. Jokiel, A. Uebleis, and H. Boehni, "Corrosion and protection characteristics of zinc and manganese phosphate coatings," Surface and Coatings Technology, vol. 88, no. 1-3, pp. 147-156, 1997.

[32] R. A. Surmenev, M. A. Surmeneva, and A. A. Ivanova, "Significance of calcium phosphate coatings for the enhancement of new bone osteogenesis - A review," Acta Biomaterialia, vol. 10, no. 2, pp. 557-579, 2014.

[33] S. R. Paital and N. B. Dahotre, "Calcium phosphate coatings for bio-implant applications: materials, performance factors, and methodologies," Materials Science and Engineering: R: Reports, vol. 66, no. 1-3, pp. 1-70, 2009.
[34] S. V. Dorozhkin, "Calcium orthophosphate coatings on magnesium and its biodegradable alloys," Acta Biomaterialia, vol. 10, no. 7, pp. 2919-2934, 2014.

[35] F. Feyerabend, H.-P. Wendel, B. Mihailova et al., "Blood compatibility of magnesium and its alloys," Acta Biomaterialia, vol. 25, pp. 384-394, 2015.

[36] W. Kim, K. Han, J. Kim et al., "Effect of surface area on corrosion properties of magnesium for biomaterials," Metals and Materials International, vol. 19, no. 5, pp. 1131-1137, 2013.

[37] Y.-T. Liu, K.-C. Kung, T.-M. Lee, and T.-S. Lui, "Enhancing biological properties of porous coatings through the incorporation of manganese," Journal of Alloys and Compounds, vol. 581, pp. 459-467, 2013.

[38] L. Cao, L. Wang, L. Fan et al., "RGDC peptide-induced biomimetic calcium phosphate coating formed on AZ31 magnesium alloy," Materials, vol. 10, no. 4, article no. 358, 2017.

[39] Y. Su, Y. Guo, Z. Huang et al., "Preparation and corrosion behaviors of calcium phosphate conversion coating on magnesium alloy," Surface and Coatings Technology, vol. 307, pp. 99-108, 2016.

[40] Y. Su, Y. Su, Y. Lu, J. Lian, and G. Li, “Composite microstructure and formation mechanism of calcium phosphate conversion coating on magnesium alloy," Journal of The Electrochemical Society, vol. 163, no. 9, pp. G138-G143, 2016.

[41] C. J. Bettles, M. A. Gibson, and K. Venkatesan, "Enhanced agehardening behaviour in Mg-4 wt.\% Zn micro-alloyed with Ca," Scripta Materialia, vol. 51, no. 3, pp. 193-197, 2004.

[42] L. Kouisni, M. Azzi, M. Zertoubi, F. Dalard, and S. Maximovitch, "Phosphate coatings on magnesium alloy AM60 part 1: Study of the formation and the growth of zinc phosphate films," Surface and Coatings Technology, vol. 185, no. 1, pp. 58-67, 2004.

[43] S. Shadanbaz and G. J. Dias, "Calcium phosphate coatings on magnesium alloys for biomedical applications: a review," Acta Biomaterialia, vol. 8, no. 1, pp. 20-30, 2012.

[44] G. Wang, N. Cao, and Y. Wang, "Characteristics and corrosion studies of zinc-manganese phosphate coatings on magnesiumlithium alloy," RSC Advances, vol. 4, no. 104, pp. 59772-59778, 2014.

[45] Y. Su, Y. Lu, Y. Su, J. Hu, J. Lian, and G. Li, "Enhancing the corrosion resistance and surface bioactivity of a calciumphosphate coating on a biodegradable AZ60 magnesium alloy via a simple fluorine post-treatment method," RSC Advances, vol. 5, no. 69, pp. 56001-56010, 2015. 

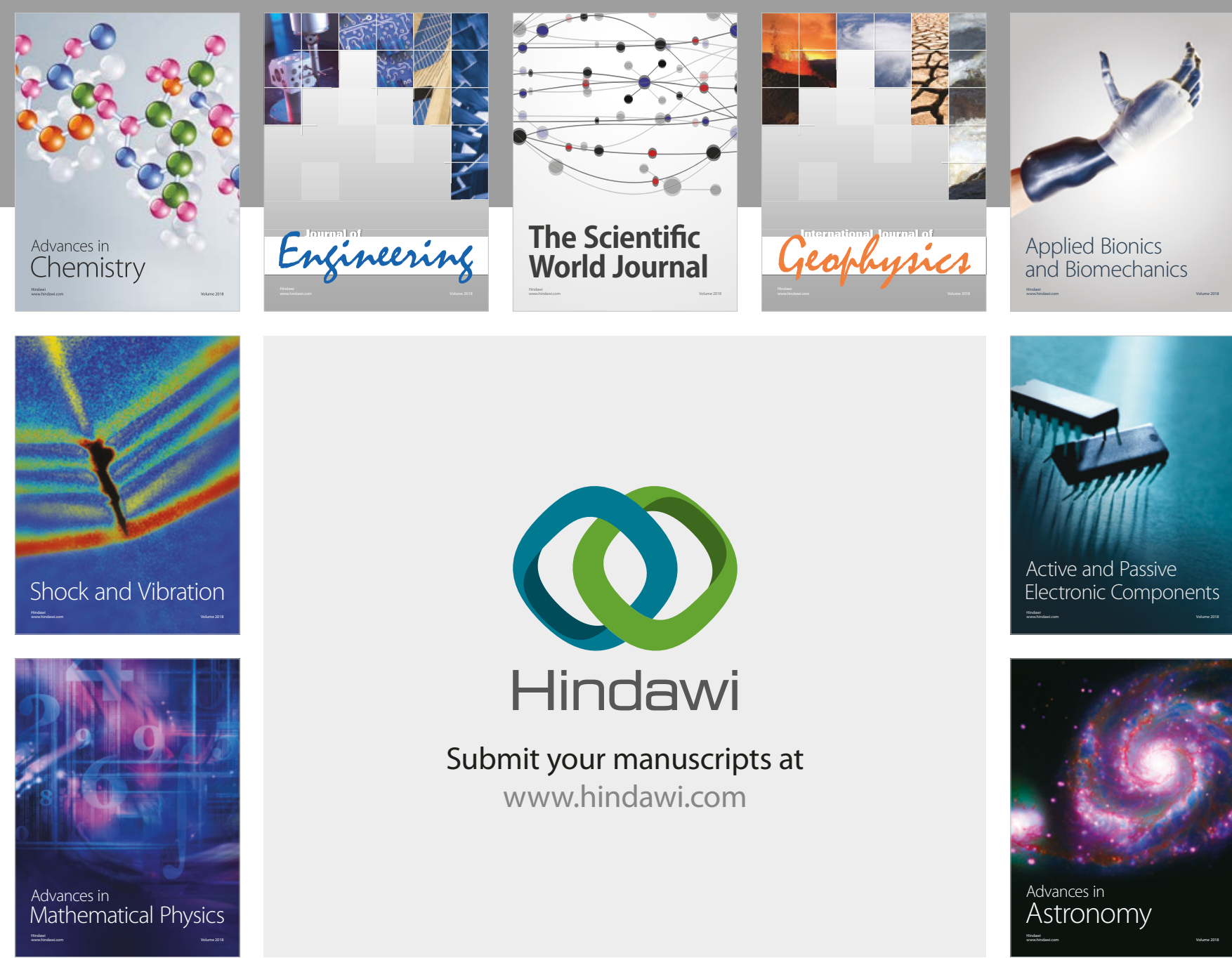

Submit your manuscripts at

www.hindawi.com

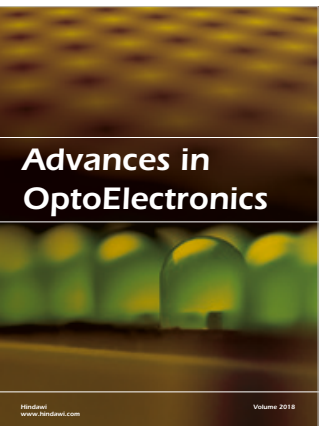

\section{Rotcting Machinery}
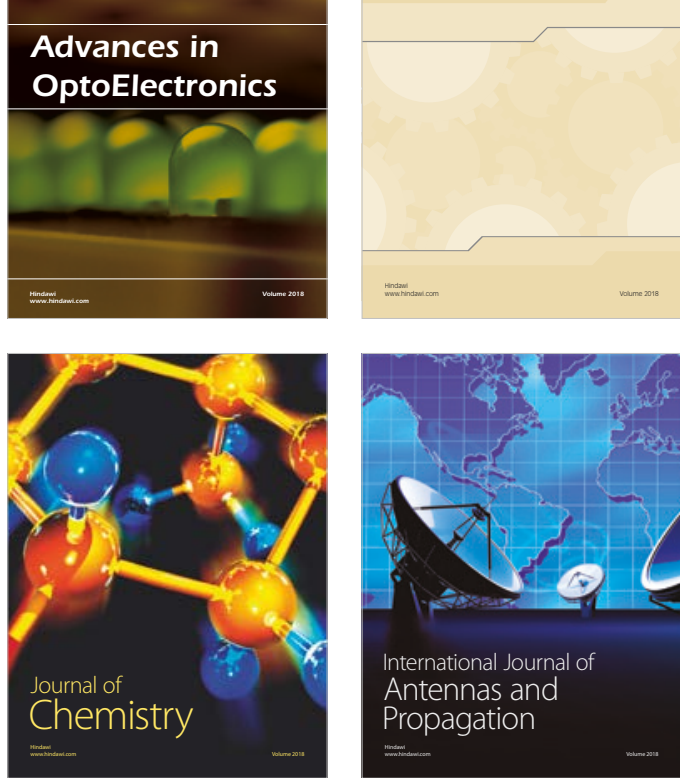

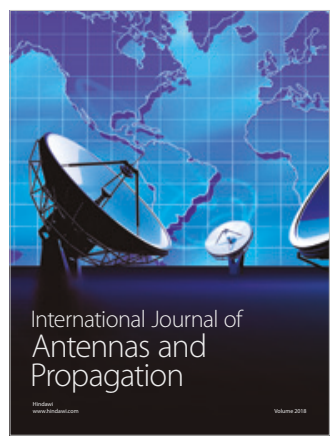

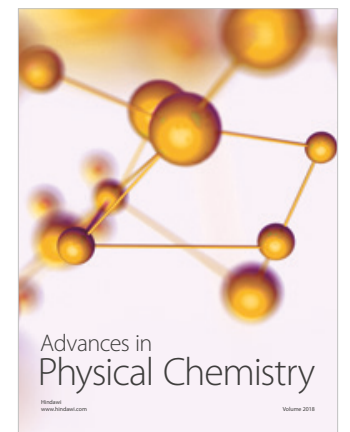

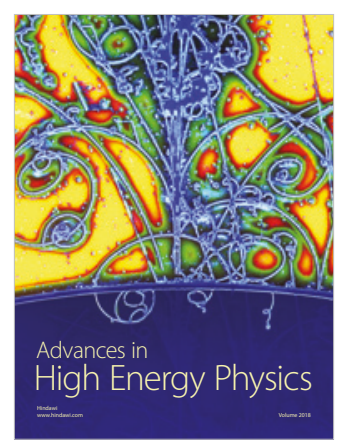

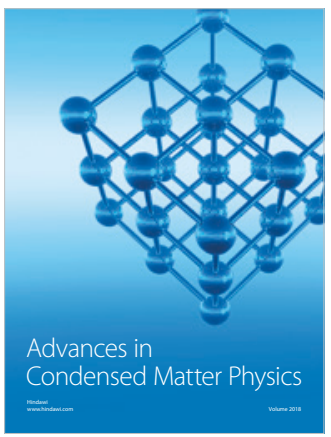

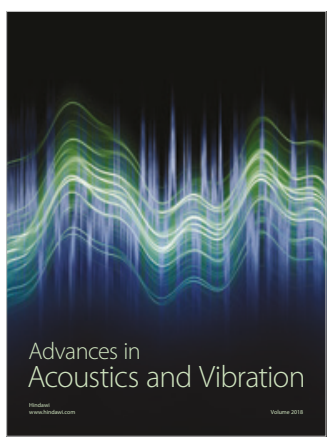

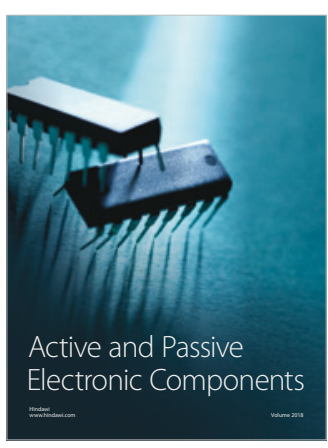
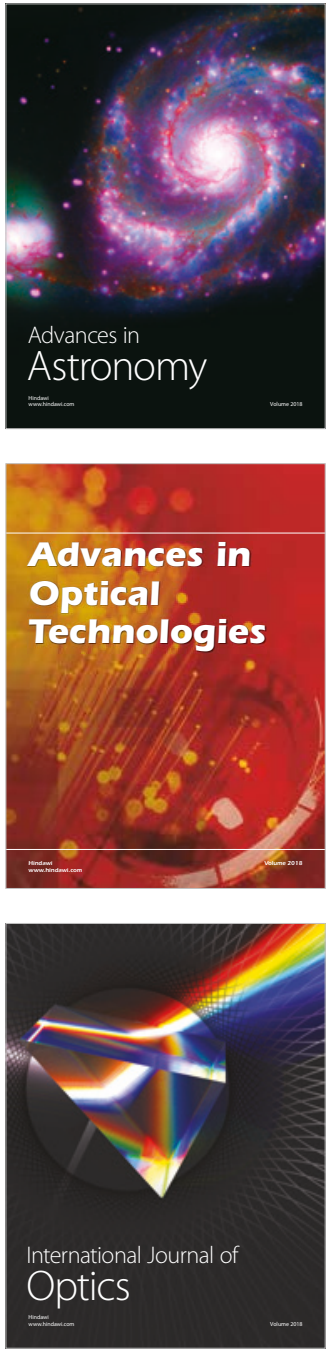